
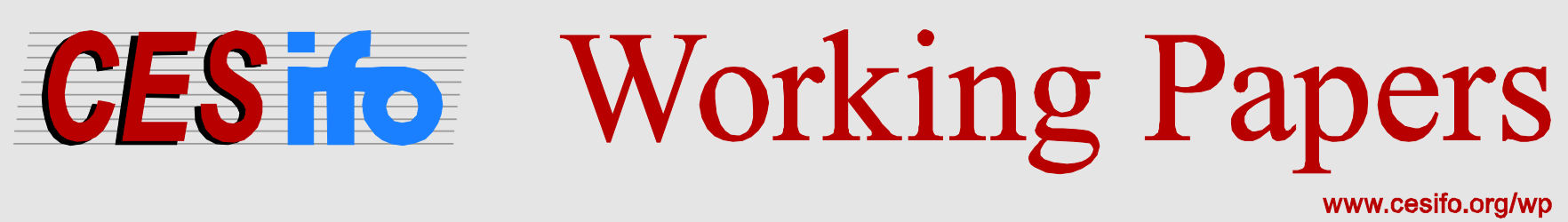

\title{
To Leave or Not to Leave? \\ Climate Change, Exit, and Voice on a Pacific Island
}

\author{
Ilan Noy
}

\author{
CESIFO WORKING PAPER NO. 6227 \\ CATEGORY 10: ENERGY AND CLIMATE ECONOMICS \\ DECEMBER 2016
}

An electronic version of the paper may be downloaded

- from the SSRN website:

- from the RePEc website:

- from the CESifo website:

wWw.SSRN.com

Www.RePEc.org

www.CESifo-group.org/wp 


\title{
To Leave or Not to Leave? Climate Change, Exit, and Voice on a Pacific Island
}

\begin{abstract}
Observers repeatedly predict that climate change will lead and is already causing massive migration with very large numbers of people forced to leave their homes in cataclysmic waves of climate refugees. Yet, most of the empirical research on the contemporary link between climate change and migration fails to find much evidence of this migration. As climate change has been progressively intensifying for decades, should we not expect these migrations to already be happening? Here, we focus on Tuvalu, a small atoll nation in the South Pacific, that in many respects can serve as the Canary-in-the-Mine for climate change research. If migration driven by climate change is not happening today, Tuvalu may explain why. One plausible reason for this lack of migration is the desire by Tuvaluans to Voice. 'Voicing', a concept borrowed from Hirschman's Exit, Voice, and Loyalty, is the advocacy expressing one's wish for change. We present evidence that the atoll nations have decided that their best policy at this point in time is to stay and Voice. If it is not unique to the Pacific atolls, this present choice to prefer Voice to Exit may explain why the evidence on climate-induced migration is so fragile. Tuvalu may be using Voice to attempt to avert dire outcomes, or to strengthen its bargaining position for the inevitable discussions about compensation. Still, the biggest risk may be that the equilibrium mix between Voice and Exit is unstable and that the transition from one strategy to the other may be abrupt-probably in response to a catastrophic natural disaster. In the longterm, sudden and unplanned displacement are always less successful, so advance planning is necessary now, including the financing of alternatives from funding through the Warsaw International Mechanism for Loss and Damage.
\end{abstract}

JEL-Codes: Q000.

Keywords: migration, climate change.

\author{
Ilan Noy \\ School of Economics and Finance \\ Victoria University of Wellington \\ PO Box 600 \\ New Zealand - 6140 Wellington \\ ilan.noy@vuw.ac.nz
}


To Leave or not to Leave? Climate Change, Exit, and Voice on a Pacific Island

Ilan Noy*

Victoria University of Wellington, New Zealand

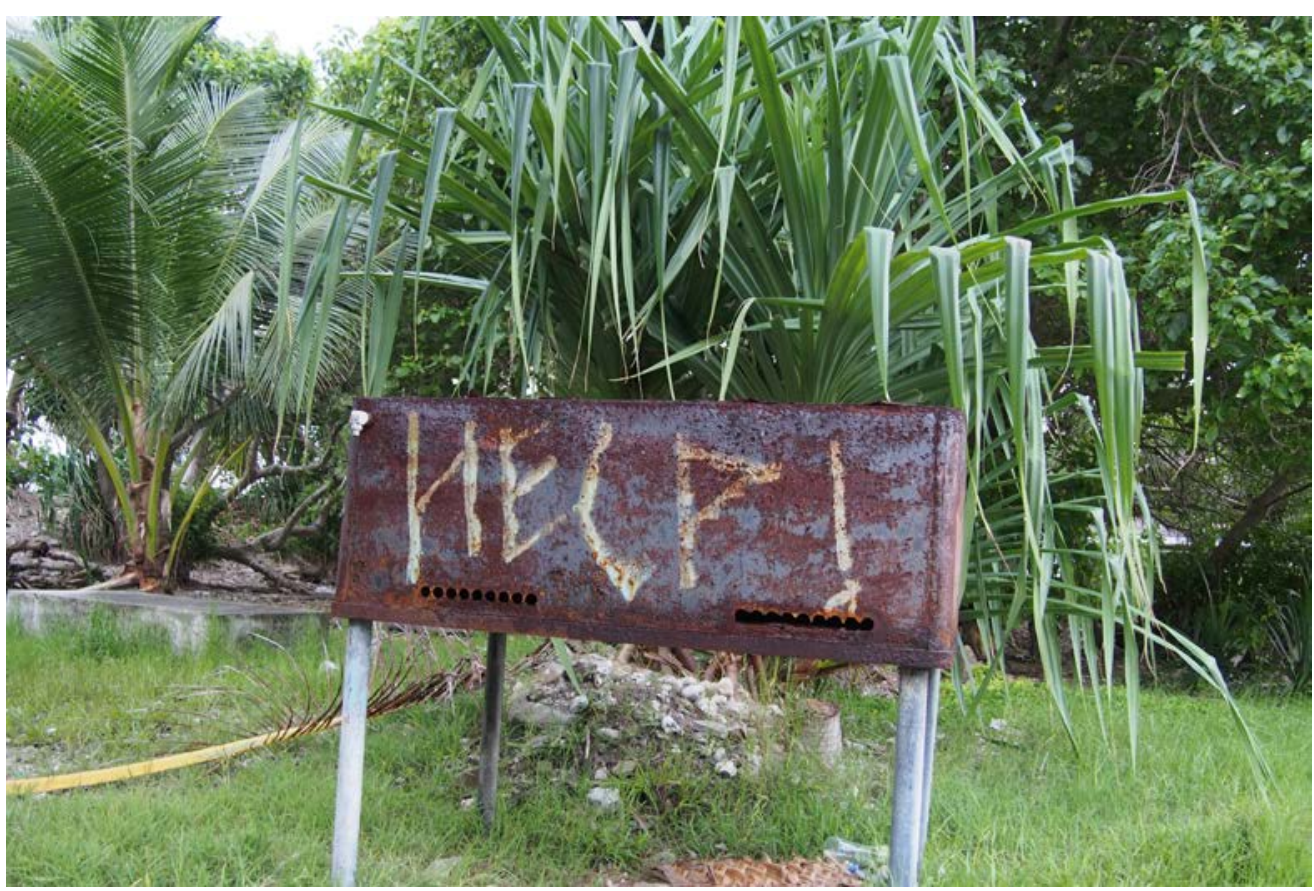

* Chair in the Economics of Disasters and Professor of Economics, School of Economics and Finance, Victoria Business School, POB 600, Wellington, New Zealand. ilan.noy@vuw.ac.nz. The photo was taken by the author in Funafuti, Tuvalu, in 2014. 
"Fundamentally, we need world leaders to develop a new kind of Marshall Plan...to meet the costs of adaptation. The money we put into adaptation now will save billions of dollars in compensation for climate change damages in years to come. If urgent action is not taken in addressing the adaptation needs of vulnerable countries, we will be forced to go down the path of litigation. For a highly vulnerable country like Tuvalu, we cannot just sit back and watch our homeland slowly disappear. If necessary, we will use whatever legal means available to us to seek the necessary restitution for all damages created by climate change."

Prime Minister of Tuvalu, Apisai lelemia (2007)

\section{Introduction: Migration and Climate Change}

Climate change will lead to massive migration with very large numbers of people forced to leave their homes in cataclysmic waves of climate refugees. This is an oftenrepeated prediction. "Every year, millions of people are forcibly displaced by floods, tropical storms, earthquakes, droughts, glacial melting, and other natural hazards. Many find refuge within their own country but some have to move abroad. In the context of climate change, such displacement is likely to increase." (Nansen Initiative, 2015). Internal displacement due to natural disasters was put at almost 20 million people in 2015 alone (IDMC, 2016). Some of the predictions about future displacement/migration because of climate change are apocalyptic, predicting hundreds of millions of people on the move across international borders (e.g. Hsiang and Sobel, 2016). ${ }^{1}$

Most of the empirical research on the contemporary link between climate change and migration, however, fails to find much evidence of this migration. Using a comprehensive global dataset, for example, Beine and Parsons (2015) fail to find any evidence linking climatic changes and migration flows over time and across countries. Gröschl and Steinwachs (2016) provide a more structural estimation, based on gravity-type equations, but also fail to find much evidence of a climate-migration link.

Even in Bangladesh, widely preceived to be one of the countries most dramtically stressed by climate change from droughts, flooding, and sea-level rise, Gray and Mueller (2012) find only limited evidence of significant internal migration as a result

\footnotetext{
${ }^{1}$ Gemenne (2011) discusses, skeptically, many of the difficulties with the data and projections made on environmentally driven migrations.
} 
of natural hazards. Similarly, Dallmann and Millock (2016) find limited evidence of inter-state migration caused by droughts and floods in nearby India. Goldbach (2016) examine micro-survey evidence from Ghana and Indonesia, and also fails to uncover robust evidence of any link between environmental factors and migration decisions. ${ }^{2}$ While Kocornik-Mina et al. (2016) focus on floods more globally, and similarly fail to observe much significant internal migration in their aftermath. Barrios et al. (2006), in contrast, do find evidence of climate change impact on internal migration to urban centers, but that phenomenon is limited spatially to Sub-Saharan Africa and dependent on the historical antecedent (the unique colonial experience of that region). ${ }^{3}$

What explains this disconnect? As climate change has been progressively intensifying for decades, should we not expect these migrations to already be happening? Boncour and Burson (2010) identify several challenges in the research on human displacements caused by climate change. Among these is the need to "understand the potential scales and patterns of climate change-related migration." (p. 12). In particular they ask: "How many people will migrate and where? What migration patterns and volumes emerge in response to different environmental stressors?" (p. 14). What are the causal links between migration, environmental events and processes, and climate change? To what extent is the environment the primary driver? How do climatic and environmental drivers interact with social, political, and economic motivations for migration? (p. 16).

Here, we do not provide an empirical evaluation nor a globally relevant assessment of these numerous and very interesting questions. Instead, we focus on one country, Tuvalu, a small atoll nation in the South Pacific that in many respects can serve as the Canary-in-the-Mine for climate change research. If migration driven by climate change was indeed happening today, it should be found in Tuvalu. And if this

\footnotetext{
${ }^{2}$ Except for some specific cases in Ghana.

${ }^{3}$ In contrast with this empirical consensus, Drabo and Mbaye (2015) find that the emigration that results from natural disasters exacerbates the brain drain, and is mostly apparent for high-skilled individuals. We will return to this observation later. Raleigh et al. (2008) provide a survey of the earlier literature and also fail to identify any evidence of large-scale climateinduced migration.
} 
migration is not happening yet, observing Tuvalu may provide us explanations for its absence. I would like to suggest here that one of the reasons for this lack of migration is the desire by Tuvaluans to Voice. 'Voicing', a concept borrowed from Hirschman's (1970) Exit, Voice, and Loyalty, is the advocacy expressing one's wish for change, and that Voice often is a deliberate choice that in some circumstances may be preferred to Exit (migration).

Before analyzing Hirschman's framework and its applicability to Tuvalu, we describe the current circumstances in Tuvalu (section 2) and the forecast regarding its future climate risks (section 3). We then focus on Exit and Voice as the options facing Tuvaluans, and conclude by discussing the importance of understanding Loyalty within this context.

\section{Disasters and Tuvalu}

The Pacific Island Countries are among the most vulnerable countries, in per capita terms, to natural hazards; they experience more damage and loss associated with disasters than even other Small Island Developing States (SIDS) such as those in the Caribbean and the Indian Ocean (Noy, 2016). They are particularly exposed to the risk of tropical cyclones. Many of the Pacific Island Countries are also reliant on consistent rainfall for their water consumption and crop irrigation needs. They are thus very vulnerable to fluctuations in rainfall patterns associated with droughts and flash flooding, and the increasing frequency of rainfall extremes associated with climatic change. The atoll islands in the Pacific-small coral islands only a few meters above sea-level-face additional risks, as their vulnerability is exacerbated by climate change (in particular rising sea levels, increasing intensity of cyclones, and destruction of protective coral reefs and mangrove forests). Recently, Tropical Cyclone Pam, one of the strongest ever measured, coincided with the UN World Conference on Disaster Risk Reduction in Sendai, and reinforced this message about the extreme vulnerability of the Pacific. 
All of the Pacific Atoll Nations-Kiribati, Marshal Islands, Nauru, and Tuvalu-are exposed to storm surges associated with tropical cyclones, and tsunamis caused by earthquakes. Disaster risks in atoll islands are further compounded during periods of King tides (exceptionally high seasonal tides) and as a result of ongoing coastal erosion associated with sea level rise, coral bleaching, and loss of protective mangrove.

An apt example for the extreme vulnerability of atoll islands is the damage wrought by Tropical Cyclone Pam on Tuvalu. This cyclone passed over Vanuatu, and at an average distance of about $1000 \mathrm{~km}$ from Tuvalu. Despite this very long distance, Tuvalu's outer islands were heavily damaged, with damage estimates ranging around 10\% of GDP (Taupo and Noy, 2016). ${ }^{4}$ Tuvalu has experienced other very significant disaster events in the past several years. Most notably, and equally related to climatic change, it experienced a very severe drought in 2011.

The available data underestimates the impact on Tuvalu, and does not allow us to quantify longer-term and more indirect losses associated with reduced educational achievements and consequent declines in productivity, the cost of monitoring and controlling the spread of infectious and contagious diseases, and similar longer-term losses (Noy, 2016b). Other potential long-term losses are those associated with declining health as a result of the destruction of health facilities, the long term adverse impacts of psychological trauma, or other indirect impacts on the macroeconomy (for example on prices).

Whatever the publicly available estimates of disaster risk are, and irrespective of the degree of underestimation, it seems clear that the local populations are well aware of these risks. The main question we would like to analyse here is that given these extreme risks, why do the people of these islands choose to stay rather than migrate

\footnotetext{
${ }^{4}$ Pam did not coincide with the highest (King) annual tides. The Tuvaluan Met Service predicted that had the events coincided, the storm surge would have been almost twice as high, and would have practically inundated the affected islands where about half the population of the country resides (IFRC, 2015).The World Bank (2015) estimated the damage from cyclone Pam to Tuvalu's assets, infrastructure and agriculture at 25\% of GDP.
} 
to safer places? In order to suggest some answers to this question, we first discuss in more detail the predicted impacts of climate change in the Pacific.

\section{Climate Change and Increasing Disaster Risk in Tuvalu}

The slow trending changes in climatic conditions are unlikely to have a very large impacts on the normal weather conditions in the next few decades in the Pacific. But, they will change many of the parameters defining the threat of sudden-onset natural hazards such as tsunamis, tropical cyclones, flash and riverine floods, extreme heat periods, and slower-onset droughts. Many of these hazards are especially threatening to atoll nations like Tuvalu.

The historical record is not long enough to identify long-term trends in low-frequency events, and the available models do not provide consistent enough predictions across the different models that are currently being used. Notwithstanding this lack of certainty, the three most important issues with respect to the Pacific atoll island countries and climate change are: (1) changing frequency and intensity of extreme rainfall periods (causing flash flooding or droughts); (2) changes in the intensity, frequency, and trajectory of tropical cyclones; and (3) sea-level rise and other impacts on oceans such as loss of coral reefs and mangroves.

IPCC (2012) examines the incidence of El Niño-Southern Oscillation (ENSO), whose impact on the Pacific Islands' extreme weather patterns is significant, and observes a possibility of more frequent central equatorial Pacific ENSO events. This will thus mean both more rainfall-induced flash flooding and more or more intense droughts in the region. The intensity of El Niño events seems to have already increased significantly (Lee and McPhaden, 2010). There is also evidence that suggests an increase in total rainfall for all PICs is likely with future warming (CSIRO, 2014).

The historical record suggests that the very dramatic increase in impacts associated with tropical cyclones in the past several decades globally is largely due to increased exposure and vulnerability. Some even argue that there is no evidence at all on 
changing frequencies of tropical cyclones on the global scale (Weinkle et al., 2012; and Woodruff et al., 2013). ${ }^{5}$ Yet, even if the change in frequency of cyclones globally is not currently identifiable, there is increasingly convincing evidence of increased intensity of cyclonic activity since the mid 1970s (Emanuel, 2005). More recent work continues a step further and argues there is an observed trade-off between intensity and frequency of cyclones (Kang and Elsner, 2015). This work identifies decreased frequency but increased intensity of cyclones on a global scale. ${ }^{6}$

The current consensus forecast for the Pacific is for about $60 \mathrm{~cm}$ sea-level rise by the end of the century. But, some recent predictions regarding global sea level rise are considerably more alarming as new information on glacial melting and other feedback loops has been incorporated into climate models. Sea level rises pose obvious difficulties for Tuvalu. Shorelines are particular vulnerable, as sea-level rise will lead to continual increases in the damages caused by storm surges.

This impact will be compounded by another trend for which there is high certainty: ocean acidifications and the consequent destruction of coral reefs. Coral reefs serve as wave barriers and prevent the full force of storm surges from hitting coastal regions. According to a recent meta-estimate, coral reefs attenuate 97 percent of the storm-wave power and reduce wave height by 84 percent (Ferrario et al., 2013). Without live reefs that can re-generate and continue protecting the coasts, many areas may end up becoming much more exposed to storm surges. There is wide agreement that the combination of sea-level rise and deterioration in coral reef

\footnotetext{
${ }^{5}$ This finding is not surprising, as cyclones are small probability events, and the time series necessary to identify frequency trends in such low probability events is much longer than the available data. Crompton et al. (2011), for example, argue that one would need to have 260 years of hurricane data to identify any trends in hurricane frequency associated with anthropomorphic climate change in the Atlantic Ocean. Since South Pacific cyclones are even less frequent than Atlantic ones, the time series necessary to identify historical trends there would be even longer. Complete Pacific cyclone data is only available from 1981.

${ }^{6}$ Mei et al. (2015) find evidence of increasing cyclone intensity in the North-Western Pacific affecting another Atoll nation - the Republic of the Marshall Islands. In the South Pacific, cyclone intensity will very likely increase by $4-11 \%$ increase in wind speed, and that will result in increases in cyclone damages (World Bank, 2016). Strobl (2012) finds that cyclone damage is related to the 3.8th power of the maximum wind speed measure, in his research on Caribbean hurricanes. This suggests and increasing damage by $16-48 \%$.
} 
ecosystems will make Tuvalu considerably more vulnerable to storms, regardless of whether storms will indeed be more frequent and/or more intense.

The current projections regarding sea level rise will entail, in the long term, very high dislocation for Tuvalu. A $60 \mathrm{~cm}$ rise will permanently flood about $6-10 \%$ of the main island's land area. Holding constant the strength of storm surges and king tides, however, this sea level rise may expose a further $10-11 \%$ of land area to these occasional inundations. ${ }^{7}$ The most significant climate-related risk, however, for Tuvalu, is the risk of storm surges. This risk is already very high, and with sea level rise and the deterioration of the ocean's ecology this risk will become greater.

Typically, disaster risk is perceived as the interaction between the hazard (in terms of both frequency and severity), people's exposure to it, and their vulnerability to its impact. Hazard risk for Tuvalu will likely increase as a result of climate change, but changes in exposure and vulnerability may exacerbate this. Projected population growth rates for Tuvalu and other Polynesian Pacific Island countries are fairly low, but Tuvalu is experiencing urbanization and increasing population density on its main island (Funafuti). Previous research shows that the relationship between disaster risk and incomes depends on the degree of hazard exposure. In high hazard countries, increased income is associated with increased damages from disasters. Damages, in this case, increase at about the rate that incomes grow, so that the ratio of damages to GDP remains constant. ${ }^{8}$

\footnotetext{
7 These calculations are based solely on elevation maps of the island, using a 'bathtub fill' approach as in Shepard et al. (2012). Yamano et al. (2007) point out that the main island (Funafuti) includes significant land area that was reclaimed, and will likely flood in future events. On the other hand, Kench et al. (2015) investigate the historical record for Funafuti, and conclude that the atoll island appears to be rising together with the sea level (it is a living coral). However, they point out that it is unlikely that this process will be maintained as the speed of sea-level rise is increasing and corals are dying.

${ }^{8}$ Raschky (2008) finds a non-linear relationship between income per capita and disaster damages, with a decrease in disaster damages (as share of GDP) that is declining as per capita incomes increases, but at a decreasing rate. Schumacher and Strobl (2011), however, note that this declining damages (as share of GDP) is only observed in low-risk countries. For high-risk countries, the ratio of damages to GDP appears constant as incomes increase.
} 
To summarise, all the available evidence suggests that disaster risk in Tuvalu is likely to increase signficantly in coming decades. It will increase as: (1) the hazard intensity (mostly cyclones and droughts) increase; (2) as more people will be exposed because of population growth, urbanization and movement to the capital Funafuti, and sealevel rise; and (3) as households will be increasingly more vulnerable given their increasing reliance on man-made infrastructure and imported goods (Taupo et al., 2016).

An important additional issue is the observation that in Tuvalu it is often the poor that live in hazard prone areas (Taupo et al., 2016). Thus, the poor, who are always more vulnerable, become even more so because of changes in climate patterns. As such, the increasing exposure to hazards will concentrate mostly among the poor, and will exacerbate growing inequality in affected communities. The poor are also least able to migrate internationally.

\section{Anything but migration?}

In the short term, there is little control one can exert on the frequency or intensity of the hazards facing Tuvalu; but policies can reduce exposure and vulnerability. In the long term, global policies, like the 2015 Paris Agreement, can also change the hazards, but are unlikely to yield any positive benefits in the next couple of decades as the trends in terms of hazard intensity and sea-level rise seem inevitable in these time frames. It is therefore difficult to see how any preventive action now can lead to a dramatically changed trajectory for Tuvalu, given its extreme constraints and handicaps.

The literature on disaster risk reduction consistently finds that constructing efficient and timely warning systems is clearly the most efficient policy intervention to reduce exposure. It is also probably politically the least controversial and most easily implementable. ${ }^{9}$ An early-warning system for cyclones is widely credited with

\footnotetext{
${ }^{9}$ See, for example, the conclusions on the prioritization of various development projects included in Lomborg (2013).
} 
reducing the death toll from cyclone Pam in Vanuatu in 2015, and to a lesser extent the amount of damages in Tuvalu (Taupo and Noy, 2016).

Early warning systems have been prioritized-by governments, by the World Bank, and other development partners-for some time. The magnitude of benefits, in terms of life saved per dollar spent, are typically very large if these systems manage to prevent the very catastrophic disasters that occur all too frequently. Early warning systems, however, can save lives, but cannot save livelihoods, and may be significantly less useful if an early warning cannot be followed by any useful action to reduce damages. This is the case in extremely exposed places like Tuvalu, where, essentially, there is 'nowhere to run.'

In the short-term, strengthening public infrastructure, may be a cost-effective way to reduce both damages and the indirect losses associated with their failure to provide services after sudden-onset disaster event. In normal circumstances, the indirect impacts of failure in horizonal infrastructure (water, electricity, etc.) are especially large, so investment in resilient infrastructure is likely to be cost effective. In Tuvalu's case, however, the infrastructure is so exposed to disaster risk that maintaining it will prove to be prohibitively expensive if the climate change impacts that are forecasted will indeed eventuate.

Vulnerability, in contrast with exposure on an atoll island, is closely aligned with poverty. Reducing poverty and increasing the access of the poor to resources (economic, political and social) contribute to enhance resilience and reduce vulnerability to disasters (Hallegatte et al, 2017). Vulnerability can be further reduced after disaster strikes through 'build back better' policies that enhance resilience and reduce exposure and vulnerability. Disasters should thus be seen also as an opportunity to reconstruct infrastructure, and even institutions and social arrangements in ways that addresses the vulnerabilities that were exposed by the event, and guarantees that a future hazard event will have less of an adverse impact on the exposed region. Even if this was a common occurance elsewhere, it is difficult to identify the opportunities for build-back-better in the Tuvaluan context. 
Oftentimes, in fact, these are missed opportunities elsewhere as well, and 'build back better' policies are often rigged so they channel money and privelege to benefit entrenched elites, rather than provide the benfits they tout.

Investing in 'hard resilience' may also be a strategy that could be pursued and could also be successful. This can be done by atoll raising, land reclamation and beach nourishment projects, hard coastal protection, and desalination facilities (to compensate for the loss of fresh water lens). All of these are feasible, and prohibitively expensive. One large project recently approved to be funded by the Green Climate Fund is spending of almost USD 39 million on 'hard resilience' in three Tuvaluan islands (GCF, 2016), thus protecting 3100 people from moderate storm surge risks. This is the second stage of a project in which about USD 8 million were already spend on hard protections in the main island of Funafuti. Whether these can provide long-term solutions for Tuvalu seems doubtful. The current projects are not designed for exceptionally strong storms, and are not designed with any significant accommodation for sea-level rise. If sea level rise and storm intensity indeed increase (as is widely excpected) these projects will not be sufficient.

\section{To Leave or Not to Leave?}

The last option available if protection proves infeasible or too costly is migration. Tuvaluans are Polynesians - possibly the most ambitious migratory people in world history having managed to settle on virtually every inhabitable island in a vast expanse of the Pacific. ${ }^{10}$ In more recent times, Tuvaluans have had intensive experience with temporary migrations, most recently as seafarers working in the international merchant marine fleet. Fifteen percent of Tuvaluans have temporarily migrated in the past decade (UN-ESCAP, 2016). The more permanent immigrant populations of Tuvaluans are found mainly in Fiji, New Zealand, and Australia.

\footnotetext{
${ }^{10}$ The Polynesian Triangle encompasses the whole area between Hawaii, Rapa Nui (Easter Island), and Aotearoa (New Zealand), and includes the major island groups of Tonga, Samoa, and French Polynesia and several smaller groups.
} 
Previous experience with forced migrations in the Pacific shows that if migrations are unplanned and done hurriedly in response to sudden-onset events, the outcomes for the displaced populations can be decades of dislocation and difficulty. The experience of the people of Manam Island, Papua New Guinea, evacuated in emergency circumstances in 2005 because of volcanic activity, demonstrates many of the difficulties that will likely be experienced by other displaced people in the Pacific (Connell and Lutkehaus, 2016).

About 9000 people were evacuated from Manam, and settled on the Papuan mainland. In the past decade, they have faced significant conflicts with the local populations, principally around land and access to common resources. They are mostly still living in "care centres" - former plantations that were originally arranged as temporary centres to accommodate the Manam islanders after they were evacuated. A decade after the evacuation, plans for a permanent settlement are still being developed, and are far from being implemented. The experience of the Manam islanders is the most recent, but is not unique. Previous evacuations, for example, were from Bikini Atoll as a result of nuclear testing, and the Banaba islanders from Kiribati because of environmental degradation and mining interests. Almost all were generally unsuccessful in that the migrants faced and are still facing significant difficulties in their new homes and their legal status is disputed.

In the last few years, the Government of Tuvalu has progressively discussed migration more and more vocally as a possible outcome of climate change. At this point, however, Tuvalu does not have plans nor has it initiated any planning for communitywide migration of the remaining Tuvaluans (about 10,500 people currently live in Tuvalu). The dire future that is predicted for Tuvalu is obvious, as none of the solutions that can be provided by disaster risk reduction and climate change mitigation and adaptation measures at any reasonable cost are sufficient. The question we consider here is why does the government and the people of Tuvalu engage in no deliberate planning for migration to other Pacific Islands or to the other potential destinations of Australia and New Zealand? 
Survey data show that the vast majority of Tuvaluans did not view climate risk as a major reason for concern less than a decade ago, and were not, at that time, preparing to migrate because of climate change (Mortreux and Barnett, 2009). ${ }^{11} \mathrm{~A}$ more recent survey found that only $8 \%$ of Tuvaluan wanted to migrate but could not (UN-ESCAP, 2016).

As part of a household survey conducted recently after cyclone Pam hit in 2015, Tuvaluans living in the outer islands were asked about their views on relocation as a climate change adaptation option. Forty one percent of households stated that they have already considered moving away from their current homes to safer places, while a full $86 \%$ of households will consider moving if given an option of relocation by the government. ${ }^{12}$ When they were asked about the reasons for their choice to remain, for now, in cyclone prone areas, they overwhelmingly stated that the decision not to move away is driven by financial consideration. The lack of financial resources to permit a move was by far the dominant concern with more than half of the households mentioning it (see Figure 1).

Figure 1: Reasons for non-relocation decision

(a) Reasons not to move away from cyclone prone areas

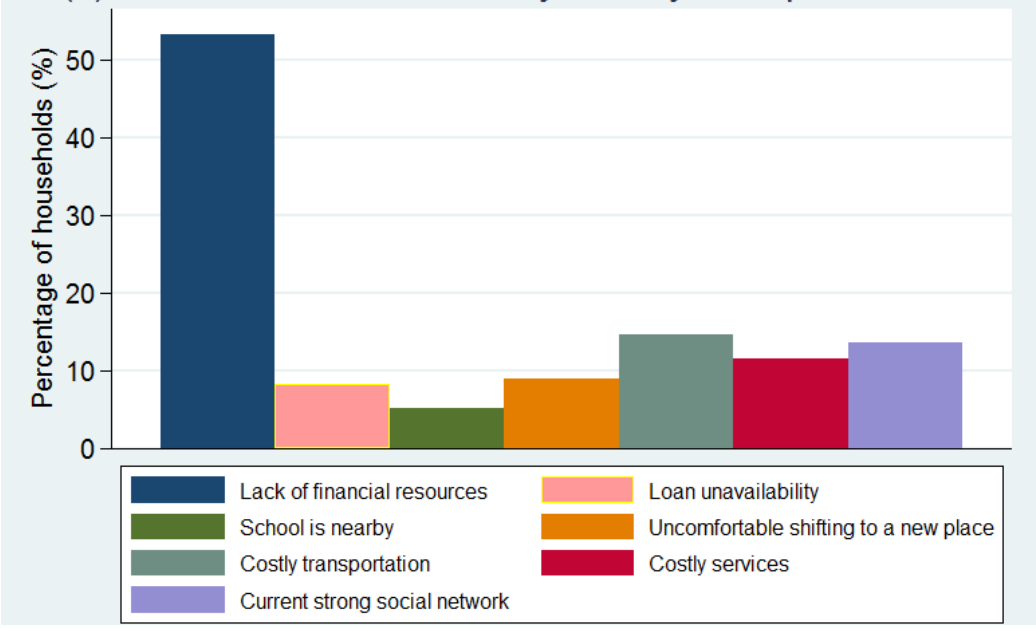

Note: The survey from which these data were obtained is described in Taupo and Noy (2016).

\footnotetext{
${ }^{11}$ More recent data also seem to suggest that Tuvaluans are, to a large extent, not prioritizing planning for migration away from the islands.

${ }^{12}$ Another survey found that $70 \%$ would like to move if climate change impacts worsened (droughts, sea-level rise, and floods) (UN-ESCAP, 2016).
} 
Residents were then asked what are the main characteristics that will be important to them when choosing the destination (Figure 2). Maybe surprisingly, strong social ties, schooling and transportation appear of only secondary importance. Of the factors influencing the choice of relocation destination, the availability of jobs appears of paramount importance (as does the availability of medical facilities).

Figure 2: Desired Characteristics of Destinations

(b) Factors influencing decision to relocate

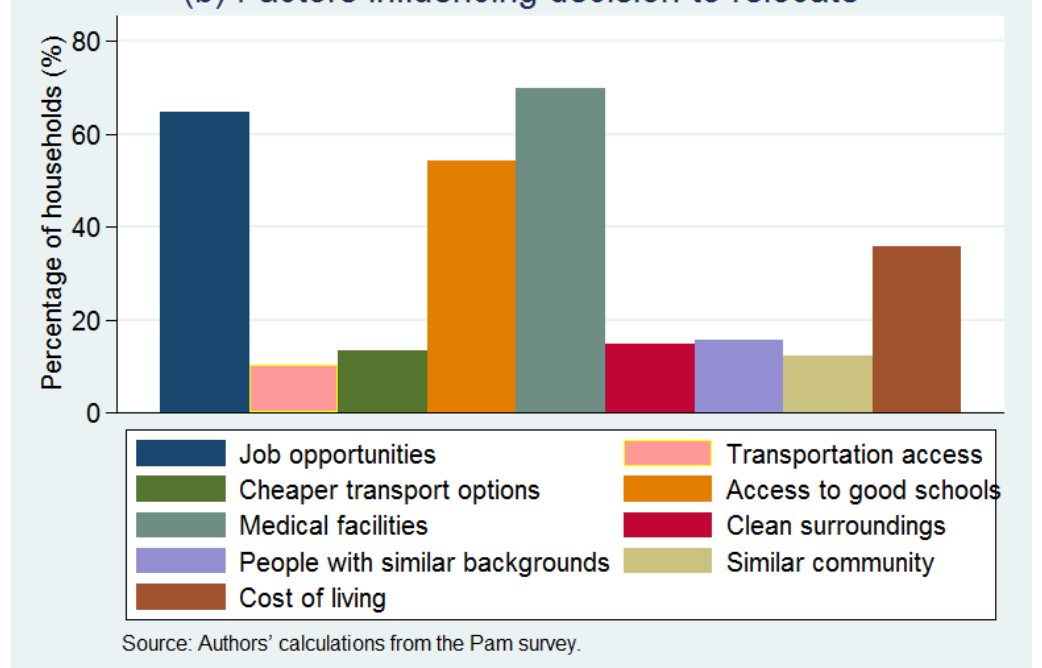

Note: The survey from which these data were obtained is described in Taupo and Noy (2016).

\section{Exit, Voicy, Loyalty}

The discordance between the stated views of Tuvaluans in surveys, the public actions or lack thereof of the Tuvalu government, and the reality of the scientific consensus regarding climate change, needs explaining. In Figure 3, we present a model of environmentally induced migration adapted and simplified from Black et al. (2011). In that model, the decision to migrate is derived from macro drivers (such as the political conditions in the country of origin), micro drivers (such as the specific identity of the migrant - religious, ethnic, linguistic), and is affected by a set of intervening circumstances (such as legal barriers to migration, or the links to a diaspora).

Figure 3: Drivers of Migration 


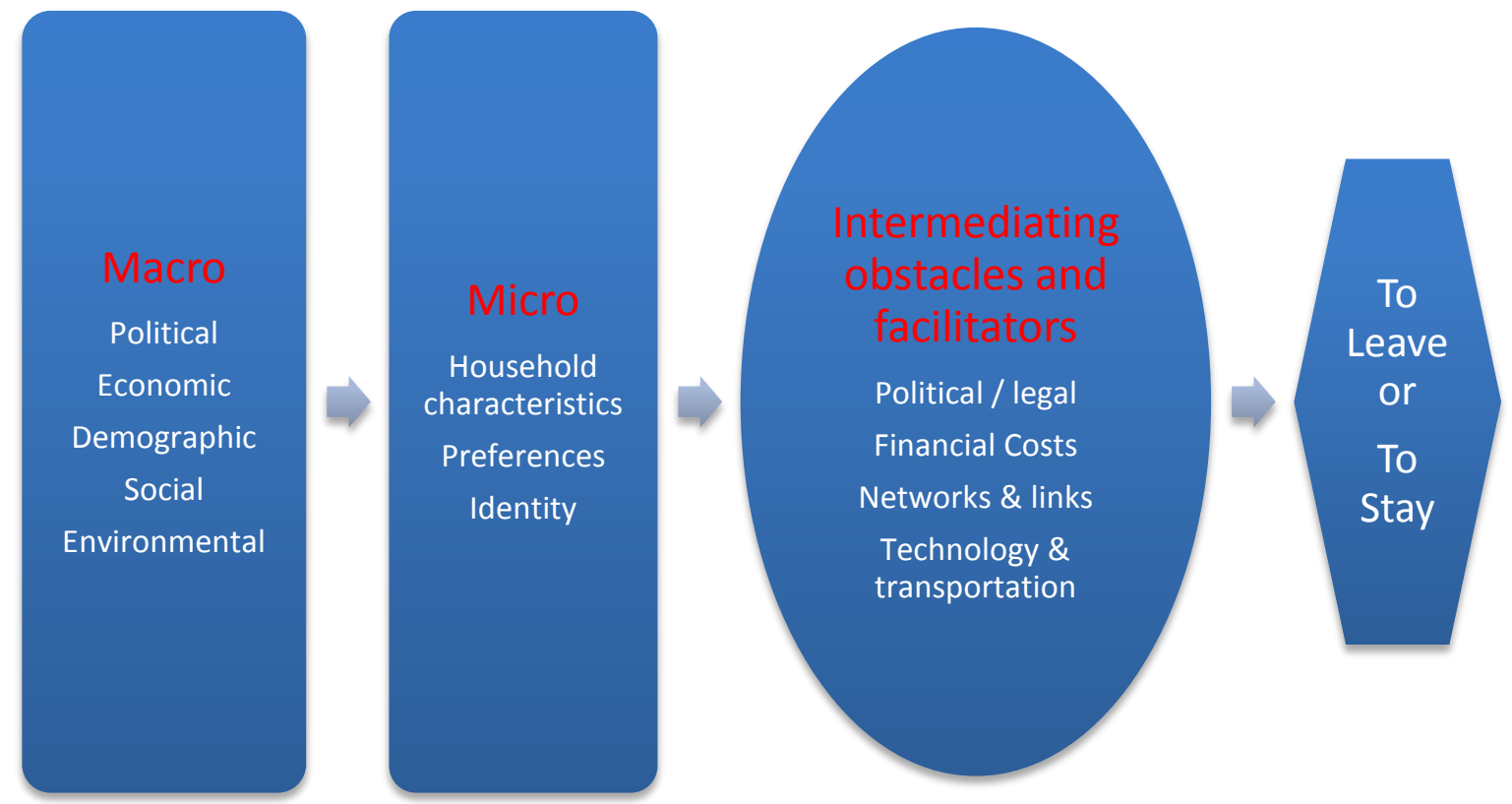

Note: adapted and simplified from Black et al. (2011), p. S5.

Climate change affects the environmental (macro) driver directly, but it also affects all other macro drivers indirectly by, for example, changing the profitability of certain economic activities. Climate change may also have an impact on some of the micro drivers by, for example, modifying the attachment of the migrant to a specific location. Less transparently obvious are the ways in which climate change may change the barriers and facilitators of migration. In the long-term, however, climate change may change, for example, the legal barriers that inhibit (or sometime enable) migration or the costs of doing so.

Taken together, these considerations-the macro, the micro, and the intervening obstacles and facilitators-suggest we should observe more actual movement of Tuvaluans away from their homeland. We propose that at least in this specific case, there is a missing component, which may be playing a very significant role in the absence of large migrations away from Tuvalu. This significant component is Voice; or as suggested by Hirschman (1970), the dichotomous choice between Exit and Voice. ${ }^{13}$

\footnotetext{
${ }^{13}$ Hirschman's developed his framework to understand, mostly, the relationship between consumers and the firms that produce the products they consume. This paper, however, is not the first to use his framework to analyze migration choices (e.g., Colomer, 2000, Hoffman, 2010).
} 
In Hirschman's description, economic analysis typically evaluates the dichotomous choice between Exit (in this case, exit=migration) and Loyalty to the status quo. This choice is paradigmatic in the 'Public Choice' literature. On the other hand, political scientists focus on the choice between Voice (protest) and Loyalty to the status quo. His analysis, in contrast, views the ability and willingness to Voice, publicly or privately, as an intermediating phenomenon that affects the dichotomous choice whether to migrate or stay. In that sense, Voice is what is missing in Black et al. (2011) framework in Figure 3.

Figure 4: Exit and Voice Configurations in Groups

\begin{tabular}{|l|l|l|l|}
\hline \multirow{2}{*}{$\begin{array}{l}\text { Examples of } \\
\text { Groups: }\end{array}$} & \multicolumn{2}{|c|}{ Exit } \\
\cline { 3 - 4 } Voice & Yes & $\begin{array}{l}|c| \\
\text { Voluntary associations } \\
\text { Political parties }\end{array}$ & $\begin{array}{l}\text { Family } \\
\text { Nation } \\
\text { Religious group }\end{array}$ \\
\cline { 2 - 4 } & No & $\begin{array}{l}\text { Manufacturers with many } \\
\text { customers }\end{array}$ & $\begin{array}{l}\text { Parties in totalitarian systems } \\
\text { Terror and criminal groups }\end{array}$ \\
\hline
\end{tabular}

Note: adapted and summarized from Hirschman (1970), p. 121.

Hirschman's framework can be represented by the two by two matrix presented in Figure 4. Nevertheless, in contrast with the diagrammatic simplicity in Figure 4, it is important to note that the choice is not always binary-i. e., on the extensive margin - and can sometime also be one of intensity. People can also choose the degree with which they pursue a strategy of Voicing, and in some cases even there could be a variation in the intensity of exit-for example, temporary vs. permanent migration.

Hirschman asks when would the Exit option prevail over the Voice option, and when would the choice be the opposite. In the Tuvalu case, we ask whether the ability to Voice, to protest against climate change and its impacts and implications, represents a valid alternative that affects the propensity to Exit? It is clear, as Hirschman points out, that the comparative efficiency of the two options - what they can achieveplay a significant role in the decision which choice is adopted. Whether people choose to Exit or stay depends on their ability to Voice, and on their perceptions 
regarding the efficacy of that Voicing. But, these factors are not the only ones affecting the migration choice.

The third vertex in Hirschman's triangle is loyalty, or in this instance adherence to the status quo of staying in place and adapting to the impacts of climate change. His framework then becomes an analysis of the role of Loyalty-the willingness to stick with the status quo-in determining when people choose to Voice or Exit (or do neither).

Voice, according to Hirschman, is more challenging than Exit, and he devotes most of his treatise to analyzing it. But, in the context of migration as Exit this may be less true, as migration is also very difficult. Migration involves a more personally significant dislocation than the abandonment of a brand or product. In any case, he points out that Voice involves several challenges:

1. Voice could lead to potential repercussions; this is especially true if Voicing is done against a community one is a member of or identifies with or if it is directed against the authorities. In these cases the activity of Voicing can lead to physical removal or social ex-communication from these communities and polities. This aspect may be less relevant in the case we analyze here, as the Voice is targeting the international community, and especially the high-income countries who are both the cause of climate change and the potential solution to it. Tuvalu itself, after all, contributed almost nothing to the accumulation of greenhouse gases, and any change in its policies will have no impact on climate change.

2. The efficacy of Voice is conditional on the influence and bargaining power of the 'actor' doing the voicing. In this case, it seems that at least relative to its size, Tuvalu (and Kiribati and the Maldives) have managed to have their Voices heard by the international community - though that of course does not mean their Voice will be heeded.

3. Who Voices also matters. In this case, it seems that the mobilization of the governments of these three countries (Maldives, Kiribati, and Tuvalu) has been relatively successful. The former Prime Minister of the Maldives (2008-2012), 
Mohamed Nasheed, and the former President of Kirbati (2003-2016), Anote Tong, have both managed to attract international attention that is clearly without precedent when considering their size. Voice is more effective when it is expressed collectively, and the three activist Atoll Nations have managed to speak, to a large extent, in one Voice in the international arena.

4. Last, but maybe not least, effective Voicing is an 'art', and using Voice is not necessarily a sufficient condition to generate change. In recent years, the concerns of the atoll nations, in spite of their miniscule size, has been quite visible in the international media. This is admittedly a very imperfect measure of the success of voicing. Clearly there are reasons to suspect that in spite of this high visibility the outcomes of climate negotiations have been woefully inadequate to fully deal with the challenges posed by climate change. Still, the Atoll Nations, and Tuvalu, Kiribati and the Maldives in particular, have managed to raise their Voice collectively, and therefore more effectively, in the international arena of climate negotiations.

If an effective Climate Agreement that manages to keep global warming within the 1.5C target set in Paris in 2015 proves infeasible, this may change the dynamic choice between Voice and Exit as faced by Tuvaluans and other atoll islanders. If that turns out to be the case, Tuvalu and its partners may decide that Voice is no longer a viable option and that will make Exit a much more pressing alternative. Exit can be viewed a 'last resort.' Permanent migration will happen-irrespective of any legal barriers-if indeed it becomes a last resort after Voicing (and the status quo) have failed. After all, almost all predictions are that the climate agreements will not be sufficient for the atoll nations.

On the other hand, Voice is more credible, and therefore potentially more effective, if Exit is ruled out as a valid, legitimate or an easy option. It is only recently that the Tuvalu government has started to publicly consider it at all. If people do not have an easy way to migrate, they will tend to Voice more forcefully, and their Voicing may be listened to more. As such, any hardening in the views against, for example, the 
granting of refugee status to 'climate refugees,' may counter intuitively increase the likelihood of more Voicing, and lead to delay in seeking to migrate. Consequently, these delays may cause worse outcomes once staying becomes untenable.

Hirschman analyzes the markets for goods, and in these regular markets, it is expected that the people that Exit first (stop purchasing or using a good or service) are the ones that have the least to lose from doing it (they have the lowest consumer surplus). In contrast, with migration, it is often the case that the people who leave first are actually the ones with higher socio-economic status, human capital, more profitable employment opportunities (the highest consumer surplus), and more entrepreneurial willingness to take risks. Bauernschuster et al. (2014) and Jaeger et al. (2010) provide recent empirical evidence for that observation.

Unfortunately, these are also the ones that are most likely able to effectively Voice concerns about climate change and generate some re-alignment of global policies. Hirschman discusses this kind of dynamics with an examination of the tensions between private and public schooling in many American cities. In his telling of this tension, the flight of more educated (typically White) elites to the suburbs led to dynamics in which the quality of the product deteriorated. This happened as the people who Exited were also those that had the ability to Voice efficiently and advocate for high standards. These dynamics might affect migration out of the Climate-affected atoll islands, as it is those with the skills and the financial wherewithal to leave that Exit first. This sort of 'Voice drain' may have an impact on the ability of those who stay to Voice their concerns, as effective Voicing demands the skills that are likely to leave.

The last component of this is Loyalty - the attachment of people to their communities and homelands. Loyalty makes Exit less likely, and therefore gives more scope and incentive for Voice. In part, it is this Loyalty that may explain why the Tuvaluan islanders have chosen to Voice, but it is probably only an imperfect explanation given the high degrees of previous temporary migrations away from the islands. 
Loyalty can weaken Voice, if outsiders perceive loyalty as making the Exit threat less credible. In circumstances when Exit is ruled out because of Loyalty we therefore also observe little Voicing. Loyalty, however, can also enhance Voice, as people are more willing to 'speak louder' if they are attached to their communities and do not want to leave them.

Hirschman points to a few other observations about Loyalty. In his telling, Loyalty may be most effective when it looks most irrational; because only then does it really change incentives sufficiently between Voice and Exit. Loyalty, the emotional attachment to place and therefore reluctance to Exit, will lead to more and stronger Voice. This inability of outside observers to understand the depth of Loyalty may explain why outsiders expect to see so much environmentally-induced migration, and do not actually see it happening.

In some cases, more Voice is needed to reach a first-best world. In this case, the firstbest world is one in which through mitigation and greenhouse gas emission reductions the change in climate is averted or minimized. Still, in the case of climate change in atoll islands, it is difficult to see even strong Voicing leading to a first-best solution to the problems of climate change, though it may seem to be a step in the right direction.

"The barrier to exit constituted by loyalty is of finite height....but it is possible for loyalty to overshoot the mark...in which the exit option is unduly neglected." (Hirschman, 1970, p. 92). On its face, this seems like a relevant concern for the Pacific atolls. We examined recent Google searches for key migration-related words in searches conducted in the atoll countries. Unfortunately, data for Tuvalu was not available, but we did obtain the statistics for Marshall Islands, Kiribati, and the Maldives (appendix A). In all these cases, the trend is, surprisingly, one of less interest in migration over the last decade.

Figure 5: Migration word searches in Google A - Maldives 


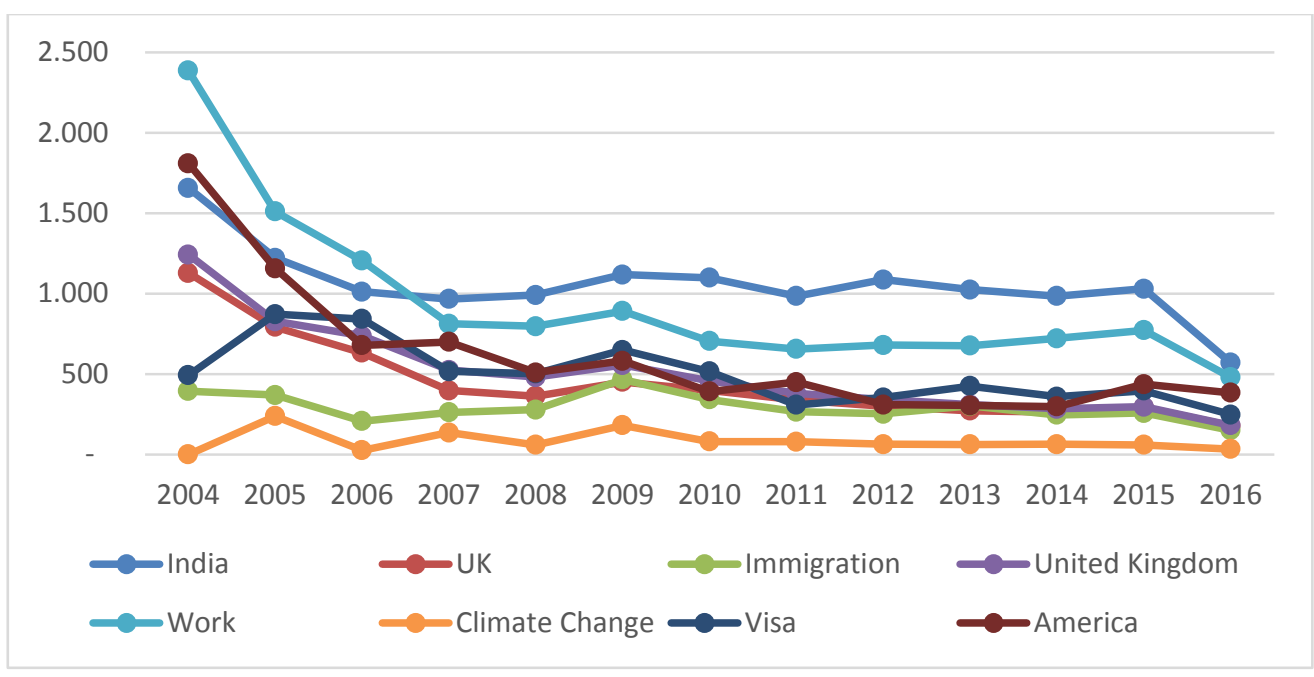

B - Marshall Islands

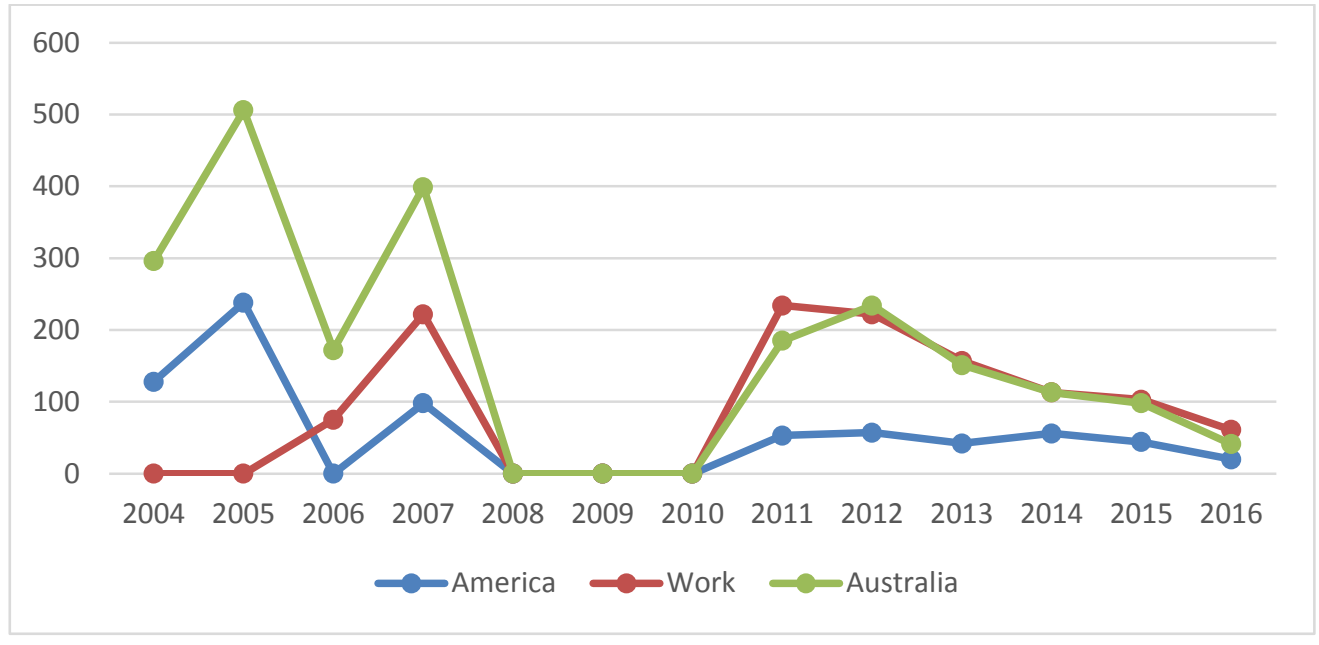

\section{C - Kiribati}

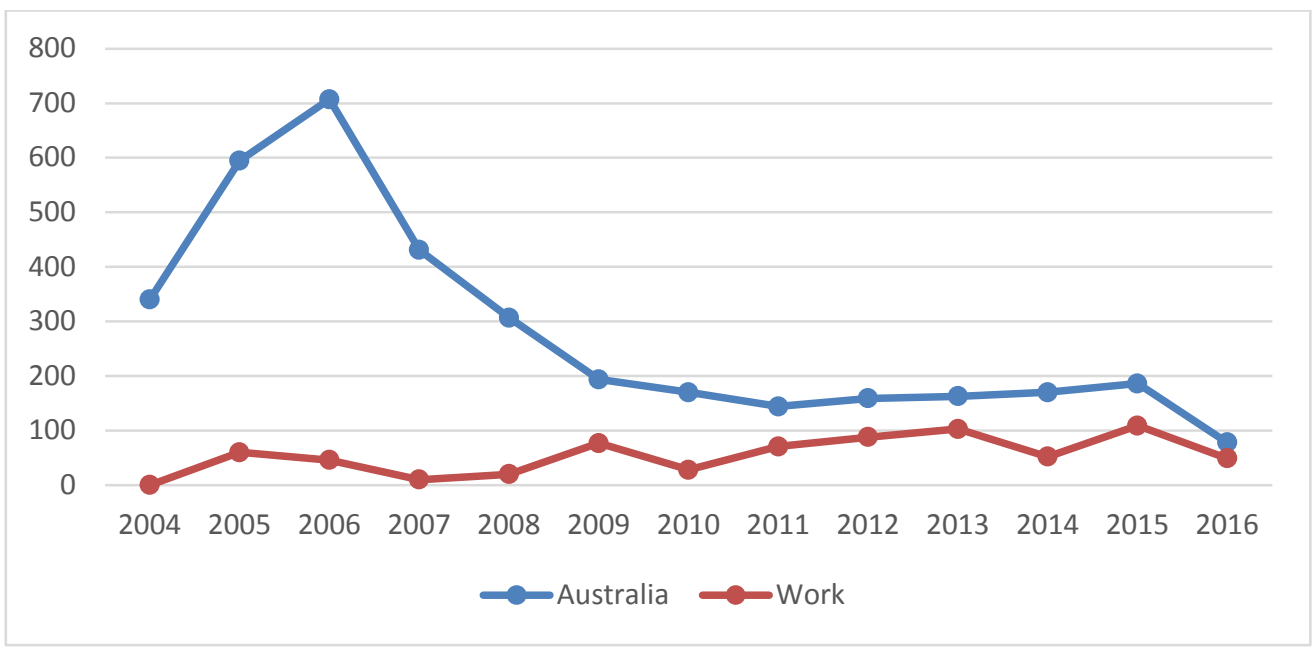

At this point, the reluctance to plan for community migration may appear reasonable since sea level rise will only make the islands uninhabitable decades from now. 
However, a more imminent concern is the interplay between sea-level rise and marine ecosystem deteriorations, on the one hand, and storm surges, on the other. In that case, loyalty may delay the planning of relocation until it is too late and displacement will happen quickly and in a haphazard manner. Previous research has clearly shown that these displacements in the Pacific that have happened quickly were generally less successful than ones in which more planning was involved.

As Hirschman puts it rather bluntly, "It is also possible, of course, that by the time the member is no longer able to close his eyes to what is going on, deterioration has become such that exit appears as the only possible reaction to the sudden revelation of rottenness." (p. 96). He even suggests that a dynamic whereby "the decision to exit will become ever more difficult the longer one fails to exit" may lead to a catastrophic delay in a decision that an outside observer may consider ludicrously late.

Counter-intuitively, people are thus less likely to abandon their Loyalty the higher the costs were of sticking with it. This is the classic 'cognitive dissonance' that prevents people from recognizing mistakes the higher is the cost of recognition (Festinger, 1957). In this case, remaining indeed entails high costs in impacts of climate extremes and there are stiff penalties for choosing Exit, so these observations generate, at least in the short-term, more Loyalty. Cognitive dissonance, however, has its limits. At some point, people abandon previously held beliefs, maybe when the evidence against them becomes overwhelming. When this threshold is crossed, it generates a sudden response, rather than a more gradual adjustment to the reality on the ground. Again, from the atoll islands perspective, this might be a cause for concern, as it suggests that people will stick with their previous policy of non-migration until, suddenly, the odds of being able to stay will become overwhelmingly small. This can then lead to a rush for the Exit, a run that cannot be but disastrous.

One major cost of Exit in this context is not only the abandonment of the community, but it is also giving up the main source of income in Tuvalu: the fishing licenses. Currently, more than $10 \%$ of Tuvaluan consumption is paid for by the fishing licenses 
that are sold to mainly to the Taiwanese fishing fleet. Tuvalu has $26 \mathrm{~km}^{2}$ of land, but about $200,000 \mathrm{~km}^{2}$ of oceanic exclusive economic zone for which the country owns the fishing rights. Finding a way to maintain soveriegnty after migration, and therefore maintain the cultural ties to the homeland and the income associated with fishing licenses, may prove to be one of the most important changes that can lead to a tipping of the scales and the start of a carefully managed and gradual retreat from the islands.

\section{Conclusions:}

It seems clear that the atoll nations have decided (explicitly or otherwise) that their best policy at this point in time is to stay and Voice. In a recent consultation among Pacific governments under the Nansen Initiative, the governments stated that their first priority at the international level is: "ensure that the Pacific region maintains a strong voice in international fora...." (Nansen Initiative, 2013, p. 9). If it is not unique to the Pacific atolls, this present choice to prefer Voice to Exit may explain why the evidence on climate-induced migration is so fragile.

As with many problems that at first glance appear intractable, the end game for the atoll nations is quite clear (e.g. Wyett, 2014). It is difficult to envision a future, a century from now, in which the island country of Tuvalu still thrives in the mid Pacific Ocean and Tuvaluans are still living on their ancestral lands. The sea-level rise that is predicted to occur under almost any climate change scenario will preclude that. At some point, Tuvaluans will start living somewhere else, at first maybe on a temporary basis. The obstacles in reaching this end game are numerous, and it is not easy to find a way to reach it while sustaining Tuvaluans' communities and culture.

Tuvalu may be using Voice to attempt to avert this dire outcome, or to strengthen its bargaining position for the inevitable discussions about compensation. That latter possibility is explicitly stated in the quote with which this paper starts. The discussion about compensation has already been set in motion in the 2015 Paris Agreement (COP21); in its endorsement, for a first time, of the Warsaw International Mechanism 
for Loss and Damage. This mechanism ultimately aims to deal with climate change impacts that cannot be averted or for whom adaptation is not possible.

The biggest risk may be that the equilibrium mix between Voice and Exit is unstable. Hirschman thus recommends "an awareness of the inborn tendencies toward instability of any optimal mix may be helpful in improving the design of institutions that need both exit and voice to be maintained in good health." (p. 126). Potentially, once Tuvaluans decide to move, the biggest hurdle they may face would be legal. People that are forced to abandon their homes because of climatic or weather conditions are not entitled to legal protection afforded to refugees fleeing persecution (including armed conflict), or stateless people. For this reason, the International Organisation for Migration chose to call them 'environmental migrants' rather than use the term 'climate refugees.' The second term is widely used in the popular press, but it does not entitle them to the same protections and rights afforded to those officially identified as refugees by the United Nations Refugee Agency. Indeed, currently environmental migrants have no rights, even in local jurisdictions.

The first draft of the new Agreement on Climate Change-the Paris COP21 Agreement-included a specific reference to the creation of a "climate change displacement coordination facility." According to Wilkinson et al. (2016) that reference, to an entity that will be in charge of planning for climate-induced relocations, was removed at the insistence of Australia. Apparently, the Australian government was specifically concerned about the creation of a status of 'climateinduced migrants' that can be applied to Tuvaluans and other South Pacific islanders and lead to pressure to resettle them in Australia.

Ultimately, Australia's opposition to a United Nations Climate Refugee Agency will no longer be ethically tenable; though recent Australian use of the 'Processing Centres' for refugees on Nauru and Papua suggest this may take a long time to be recognized. The countries that have long dominated the Pacific- New Zealand, Australia, and the 
United States-will have to play a major part in finding a solution for Tuvalu, Kiribati, and the Marshall Islands (most likely, respectively).

We should not forget that migration from low-income to high-income countries is the most successful development aid. Desmet et al. (2015) show there are massive global welfare benefits if migrations induced by sea-level rise were allowed to and indeed happened. Ultimately, allowing Tuvaluans free migration to Australia and New Zealand, while also finding a way to them to retain sovereignty over their country's marine exclusive economic zone will be a benefit to all. 


\section{References}

Barrios, Salvador, Luisito Bertinelli, Eric Strobl, 2006. Climatic change and rural-urban migration: The case of sub-Saharan Africa. Journal of Urban Economics, 60, 3, 357371.

Bauernschuster, Stefan, Oliver Falck, Stephan Heblich, Jens Suedekum, Alfred Lameli, 2014. Why are educated and risk-loving persons more mobile across regions?, Journal of Economic Behavior \& Organization, 98, 56-69.

Bedford R, Hugo G (2012) Population Movement in the Pacific: A Perspective on Future Prospects. New Zealand Department of Labour Paper.

Beine, Michel, Christopher Parsons, 2015. Climatic Factors as Determinants of International Migration. Scandinavian J. of Economics 117(2), 723-767.

Black, Richard, W. Neil Adger, Nigel W. Arnell, Stefan Dercon, Andrew Geddes, David Thomas, 2011. The effect of environmental change on human migration. Global Environmental Change 21,S1, S3-S11.

Boncour, Philippe and Bruce Burson (2010). Climate Change and Migration in the South Pacific Region: Policy Perspectives. In: Climate Change and Migration South Pacific Perspectives. Burson, B, (Ed.). Institute of Policy Studies, Victoria University of Wellington.

Colomer, Josep M., 2000. Exit, Voice, and Hostility in Cuba. International Migration Review 34(2), 423-442.

Connell, John, Nancy Lutkehaus, 2016. Another Manam? The forced migration of the population of Manam Island, Papua New Guinea, due to volcanic eruptions 20042005. International Organization for Migration.

Crompton, Ryan, Roger A Pielke, K John McAneney (2011). Emergence timescales for detection of anthropogenic climate change in US tropical cyclone loss data. Environmental Research Letters 6(1), 014003.

CSIRO (2014). Climate Variability, Extremes and Change in the Western Tropical Pacific: New Science and Updated Country Reports. Pacific-Australia Climate Change Science and Adaptation Planning Program Technical Report, Commonwealth Scientific and Industrial Research Organisation.

Dallmann, Ingrid, Katrin Millock (2016). Climate Variability and Internal Migration: A Test on Indian Inter-State Migration. Documents de travail du Centre d'Economie de la Sorbonne

Desmet, Klaus, Dávid Krisztián Nagy, and Esteban Rossi-Hansberg, 2015. The Geography of Development: Evaluating Migration Restrictions and Coastal Flooding. NBER Working Paper No. 21087. 
Drabo, A. and Mbaye, L.M. (2015) 'Natural disasters, migration and education: an empirical analysis in developing countries', Environment and Development Economics, 20(6), pp. 767-796.

Elsner, J., J. Kossin, and T. Jagger (2008). The Increasing Intensity of the Strongest Tropical Cyclones. Nature 455, pp.92-95.

Emanuel, K. (2005). Increasing destructiveness of tropical cyclones over the past 30 years. Nature 436(7051), 686-688.

Ferrario, Filippo, Michael W. Beck, Curt D. Storlazzi, Fiorenza Micheli, Christine C. Shepard, Laura Airoldi (2013). The effectiveness of coral reefs for coastal hazard risk reduction and adaptation. Nature Communication.

Festinger, L. (1957). A Theory of Cognitive Dissonance. Stanford, CA: Stanford University Press

GCF (2016). Tuvalu Coastal Adaptation Project Funding Proposal. Green Climate Fund Funding proposal package for FP015 (08/06/2016).

Gemenne, François (2011). Why the numbers don't add up: A review of estimates and predictions of people displaced by environmental changes. Global Environmental Change, Volume 21(1), S41-S49.

Gibson, John, David McKenzie, 2011. The microeconomic determinants of emigration and return migration of the best and brightest: Evidence from the Pacific. Journal of Development Economics 95, 18-29.

Goldbach Carina, 2016. Human out-migration from coastal areas in Ghana and Indonesia - The role of environmental factors. CESifo Working paper.

Government of Tuvalu, 2012. National Strategic Action Plan For Climate Change And Disaster Risk Management 2012-2016.

Gray, Clark L. and Valerie Mueller, 2012. Natural disasters and population mobility in Bangladesh. Proceedings of the National Academy of Sciences 109(16), 6000-6005.

Gröschl, Jasmin, and Thomas Steinwachs, 2016. Escaping the Weather: Do Natural Hazards Cause Migration? CESifo Working paper \#6145.

Hallegatte, Stephane, Adrien Vogt-Schilb, Mook Bangalore, and Julie Rozenberg. 2017. Unbreakable: Building the Resilience of the Poor in the Face of Natural Disasters. Climate Change and Development Series. Washington, DC: World Bank.

Hay, J., 2009: Institutional and Policy Analysis of Disaster Risk Reduction and Climate Change Adaptation in Pacific Island Countries. UNISDR and UNDP, Suva, Fiji.

Heger M, A Julca, Paddison O (2008) Analysing the Impact of Natural Hazards in Small Economies: The Caribbean Case. UNU/WIDER Research Paper 25. 
Hirschman, Albert 0., 1970. Exit, Voice, and Loyalty: Responses to Decline in Firms, Organizations, and States. Harvard University Press.

Hoffmann, B. (2010), Bringing Hirschman Back In Exit, Voice, and Loyalty in the Politics of Transnational Migration. The Latin Americanist, 54: 57-73.

Hsiang, Solomon M., \& Adam H. Sobel, 2016. Potentially Extreme Population Displacement and Concentration in the Tropics Under Non-Extreme Warming. Scientific Reports. DOI: 10.1038/srep25697.

IDMC (2016). Global Report on Internal Displacement. http://www.internaldisplacement.org/globalreport2016/.

Ielemia, Apisai (2007). A threat to our Human Rights: Tuvalu's Perspective on Climate Change. $\quad$ https://unchronicle.un.org/article/threat-our-human-rights-tuvalu-sperspective-climate-change

IFRC (2015). Nowhere to run: Tuvaluans consider their future after Tropical Cyclone Pam. $\quad$ http://www.ifrc.org/en/news-and-media/news-stories/asiapacific/tuvalu/nowhere-to-run-tuvaluans-consider-their-future-after-tropicalcyclone-pam-68429/

Jaeger, David A., Thomas Dohmen, Armin Falk, David Huffman, Uwe Sunde, and Holger Bonin, 2010. Direct Evidence on Risk Attitudes and Migration. Review of Economics and Statistics 92(3), 684-689.

Kang, Nam-Young, James B. Elsner (2015). Trade-off between intensity and frequency of global tropical cyclones. Nature Climate Change 5, 661-664.

Kench, P.S., D. Thompson, M.R. Ford, H. Ogawa, and R.F. McLean (2015). Coral islands defy sea-level rise over the past century: Records from a central Pacific atoll. Geology, 43(6); p. 515-518.

Kocornik-Mina, Adriana, Thomas K.J. McDermott, Guy Michaels, Ferdinand Rauch, 2016. Flooded Cities. Working paper.

Landsea, C.W., B. A. Harper, K. Hoarau, and J. A. Knaff (2006), 'Can We Detect Trends in Extreme Tropical Cyclones?', Science 313(5785), pp.452-454.

Lee, T. and M.J. McPhaden, 2010: Increasing intensity of El Niño in the central equatorial Pacific. Geophysical Research Letters, 37, L14603.

Li, Tim, Min Ho Kwon, Ming Zhao, Jong-Seong Kug, Jing-Jia Luo, and Weidong Yu (2010), 'Global warming shifts Pacific tropical cyclone location', Geophysical Research Letters 37, pp. L21804.

Lomborg, Bjorn (2013) Global Problems, Smart Solutions: Costs and Benefits. Cambridge University Press. 
McGranahan, Gordon, Deborah Balk and Bridget Anderson, 2007. The rising tide: assessing the risks of climate change and human settlements in low elevation coastal zones. Environment and Urbanization, 19: 17

Mechler et al. (2014). Managing unnatural disaster risk from climate extremes. Nature: Climate Change, 4, 235-237.

Mortreux, Colette, Jon Barnett, 2009. Climate change, migration and adaptation in Funafuti, Tuvalu. Global Environmental Change 19, 105-112.

Nansen Initiative, 2013. Human Mobility, Natural Disasters, and Climate Change In the Pacific: Outcome report of the Pacific Regional Consultation in Rarotonga.

Nansen Initiative (2015). Fleeing Floods, Earthquakes, Droughts and Rising Sea Levels: 12 Lessons Learned About Protecting People Displaced by Disasters and the Effects of Climate Change. https://www.nanseninitiative.org.

Noy, I. (2015). "Disasters in the Pacific: An Overview of Economic and Fiscal Issues." Pacific Economic Monitor, July.

Noy, Ilan (2016a). "Tropical Storms: The Socio-Economics of Cyclones." Nature Climate Change, 6, 343-345.

Noy, Ilan (2016b). Natural Disasters in the Pacific Island Countries: New Measurements of Impacts. Natural Hazards 84(1), 7-18.

Wilkinson E, Kirbyshire A, Mayhew L, Batra P, Milan A (2016). Climate-Induced migration and displacement: closing the policy gap. Overseas Development Institute, London.

Raleigh, Clionadh, Lisa Jordan, Idean Salehyan, 2008. Assessing the Impact of Climate Change on Migration and Conflict. World Bank.

Raschky, P. A. 2008. "Institutions and the Losses from Natural Disasters. Natural Hazards \& Earth Systems Science 8: 627-634.

Schumacher, Ingmar, Eric Strobl, 2011. Economic development and losses due to natural disasters: The role of hazard exposure. Ecological Economics 72(15), 97-105.

Strobl, E. (2012). The economic growth impact of natural disasters in developing countries: Evidence from hurricane strikes in the Central American and Caribbean regions. Journal of Development Economics, 97(1), 131-140.

Taupo, Tauisi, Harold Cuffe, and Ilan Noy (2016). "Household Vulnerability on the Frontline of Climate Change in Tuvalu." CESifo Working Paper \#6128.

Taupo, Tauisi, and Ilan Noy (2016). "At the Very Edge of a Storm: The Impact of a Distant Cyclone on Atoll Islands." CESifo Working Paper. 
UN-ESCAP (2016). Climate Change and Migration in the Pacific. United Nations University's Institute for Environment and Human Security.

Webster, P. J., G. J. Holland, J. A. Curry, and H. R. Chang (2005), 'Changes in Tropical Cyclone Number, Duration, and Intensity', Science 309 (5742), pp.1844-1846.

Weinkle, Jessica, Ryan Maue, and Roger Pielke Jr, 2012: Historical global tropical cyclone landfalls. J. Climate, 25, 4729-4735.

Woodruff ,Jonathan D., Jennifer L. Irish \& Suzana J. Camargo. 2013. Coastal flooding by tropical cyclones and sea-level rise. Nature 504.

Wyett, K. (2014). Escaping a Rising Tide: Sea Level Rise and Migration in Kiribati. Asia \& the Pacific Policy Studies 1(1), 171-185.

Yamano, Hiroya et al. (2007). Atoll island vulnerability to flooding and inundation revealed by historical reconstruction: Fongafale Islet, Funafuti Atoll, Tuvalu. Global and Planetary Change 57, 407-416. 